\title{
Cancer in Children at EI Obeid Hospital, Western Sudan.
}

El Bushra Ahmed Doumi ${ }^{1}$, Dawood Ishag Dawood ${ }^{2}$, Mohamed Guma Mohamed ${ }^{2}$, Siragelnoor Mohammed Ahmed ${ }^{2}$, Alameldin Musa Mostafa ${ }^{2}$, Zidan Ahmed Hussein $^{3}$, Maha Hamadnalla Mohammed $\mathrm{Ali}^{4}$.

\begin{abstract}
:
Background: Cancers form one of the major causes of death in children. They differ markedly from adult cancers in their nature, distribution and prognosis.

Objectives: To determine the pattern of childhood cancer at El Obeid Hospital, Western Sudan.

Patients and Methods: The records of all patients admitted with cancer aged 15 years and below to the wards of El Obeid Hospital, Western Sudan over two years were studied. The cancers were classified according to the organs affected and then ranked in their order of relative frequency. The mean age, age range, gender and the relative frequency rates were calculated.

Results: There were 40 newly diagnosed childhood cancer patients during the study period. Males were 29 patients $(72.5 \%)$. The age ranged three months to 14 years. Leukaemias were the most common malignancy in both sexes, followed by bone tumours and then nephroblastoma.

Conclusions: Cancers in children were seen at Western Sudan, and cases admitted to hospital only reflect the tip of the iceberg as many cases were directly referred to Oncology Hospitals. Establishment of a local radiation and isotopes centre is needed in this part of the country to provide oncology services and to integrate preventive programs.
\end{abstract}

Key words: Acute lymphocytic leukaemia, osteosarcoma, nephroblastoma, Western Sudan.

$\mathrm{C}$ ancer remains a leading cause of morbidity and mortality worldwide ${ }^{1}$. Much of the burden falls on developing countries where the risks associated with tobacco, alcohol, diet, industrial exposure and lack of exercise were added to cancers caused by infectious diseases $^{2}$. Cancer incidence rates have significantly increased in Sudan to become one of the major killer diseases (second in 2002) ${ }^{3}$.

The emergence of cancer as a major cause of death among children in developing countries is not well addressed.

1. General Surgeon.

2. Paediatricians.

3. Ophthalmologist.

4. $5^{\text {th }}$ year Medical student.

*Faculty of Medicine \& Health Sciences,

University of Kordofan, El Obeid, Sudan.

Correspondence to: elbushradoumi@hotmail.com
The developing countries bear the greatest burden of childhood cancers as over $90 \%$ of the children of the world live there4. It was estimated that childhood cancer, malnutrition and lack of safe water and sanitation contribute to half of all children mortality5. The patterns of childhood cancers in America and Europe were almost the same, with leukemia and central nervous system tumors accounting for over one-half of the new cases6. In contrast, lymphoma is the most common prevailing cancer of this age group in Africa7.

The objective of this study is to document the epidemiology of cancer in children seen at El Obeid Hospital, Western Sudan.

\section{Patients and Methods:}

The records of all patients admitted with cancer aged 15 years and below to the wards of El Obeid Hospital, Western Sudan during the years 2007 and 2008 were studied. 
The cancers were classified according to the organs affected and then ranked in their order of relative frequency. The mean age, age range, gender and the relative frequency rates were calculated.

\section{Results:}

There were 40 children admitted with cancer to the wards of El Obeid Hospital, Western Sudan in two years. $72.5 \%$ of the patients were males (29 cases). The age ranged from three months to 14 years with the mean age \pm Standard deviation (SD) of 6.5 years \pm 4.2 years. Six (15\%) children were from El Obeid town; whereas $34(85 \%)$ children were from distant rural locations. The diagnosis in all cases was confirmed by bone marrow aspirates, cytology, histological and radiological studies when appropriate. The type of childhood cancer was shown in table 1.

Table 1: Types of Childhood Cancer. $n=40$

\begin{tabular}{l|cccc} 
Tumour & $\mathrm{M}$ & $\mathrm{F}$ & Total & $\%$ \\
\hline Leukaemia & 13 & 03 & 16 & 40.0 \\
Bone tumours & 06 & 02 & 08 & 20.0 \\
Retinoblastoma & 02 & 02 & 04 & 10.0 \\
Nephroblastoma & 01 & 03 & 04 & 10.0 \\
Neuroblastoma & 01 & 01 & 02 & 05.0 \\
Testicular tumours & 02 & 00 & 02 & 05.0 \\
Lymphosarcoma & 02 & 00 & 02 & 05.0 \\
Hepatoblastoma & 01 & 00 & 01 & 02.5 \\
Skin tumour & 00 & 01 & 01 & 02.5 \\
\hline Total & 28 & 12 & 40 & 100.0 \\
M=males, F= females & & & &
\end{tabular}

The frequency of occurrence of different varieties of leukaemias was shown in table 2. The bone tumours were osteosarcoma of the lower femur and upper tibia in six patients and Ewing's sarcoma of the tibia in two patients.

Table 2: Leukaemias: $\mathrm{n}=16$.

\begin{tabular}{|c|c|c|c|c|}
\hline Tumour & $\mathrm{M}$ & $\mathrm{F}$ & Total & $\%$ \\
\hline Acute & 12 & 02 & 14 & 87.5 \\
\hline Lymphoblastic & & & & \\
\hline $\begin{array}{l}\text { Acute Myeloid } \\
\text { Leukaemia }\end{array}$ & 01 & 01 & 02 & 12.5 \\
\hline Total & 13 & 03 & 16 & 100.0 \\
\hline
\end{tabular}

\section{Discussion:}

In this study 40 children were seen with documented diagnosis of cancer at this hospital in two years. This did not reflect the actual situation in this community as many patients were not included due to the lack of confirmatory laboratory diagnosis, because they were seen at clinics and referred directly to oncology centres without being admitted to hospital or because many patients might not have reached health care units at all. In situations where the parents were not aware of cancer, where they rely on non medical remedies and where they lack the cost of the diagnostic tests and treatment, ascertainment of cases and hospital registries indicate only the summit of a wide base problem ${ }^{7}$.

It was interesting to notice that $85 \%$ of the patients were from rural areas, where children were brought up in the open atmosphere. In a report from Central Sudan it was observed that $66.1 \%$ of children with cancer were coming from rural areas ${ }^{8}$, what may suggest that some genetic or environmental exposures affect cancer-risk.

The distribution of the tumours was age related as we observed that commonly acute lymphoblastic leukaemia, nephroblastoma, neuroblastoma and retinoblastoma were seen in children below five years of age. Lymphomas and bone tumours occurred more frequently in the age groups of over 10 years. The majority of the patients (almost three quarters) were males. Similar age pattern and male preponderance was reported from African and other developing countries ${ }^{9,10}$.

Leukaemia was the commonest neoplasm accounted for $40 \%$ of cases. This was similar to reports from Libya ${ }^{11}$ where acute lymphoblastic leukaemia accounted for $83 \%$ of the leukaemias compared with $87 \%$ in our study (Table 2). Leukaemia was also found to be the commonest childhood neoplasm in the developed countries. This contrasted reports from African countries where lymphoma was 
the commonest tumour in many countries $^{10,} 12-14$, and rhabdomyosarcoma ${ }^{15}$ and tumours of the central nervous system ${ }^{16}$ were the commonest tumour in others. In Egypt the incidence of both lymphatic and haemopoietic cancers increased over the last decades ${ }^{17}$.

In this study bone tumours were $20 \%$ followed by retinoblastoma and nephroblastoma $10 \%$ each, compared to $5.9 \%, 2.7 \%$ and $12.8 \%$ respectively as reported from central Sudan ${ }^{8}$. Less common tumours were neuroblastoma, testicular and lymphosarcoma each accounting for $5 \%$ of the cases.

Similar to cancer in developing countries most patients were brought to our hospital in late clinical stages. Wilm's tumour was described presenting at late stage in $72 \%$ and $78.4 \%$ of patients at Nigeria ${ }^{18}$ and Sudan ${ }^{19}$. Due to absence of oncology and radiotherapy services in our hospital all patients who survived diagnostic and relevant surgical interventions were referred to higher centres, in-spite of their critical clinical status.

\section{Conclusions:}

Childhood cancers reporting to El Obeid Hospital at Western Sudan commonly arise from haematopoietic, bone and primitive embryonic tissues. The disease was found to be prevalent in our community and these documented cases only indicate the tip of the iceberg. Increasing awareness of the disease among the parents and at primary health care settings may significantly alter its course and improve the outcomes. Active plans for local oncology and radiotherapy services need urgent implementation. A regional cancer registry centre supplements the national efforts to evaluate the magnitude of the problem in order to plan future strategies.

\section{References:}

1. Kamangar F, Dores GM, Anderson WF. Patterns of cancer incidence, mortality and prevalence across five continents: defining priorities to reduce cancer disparities in different geographic regions of the world. $\boldsymbol{J}$ Clin Oncol. 2006; 24(14): 2137-50.

2. Kanavos P. The rising burden of cancer in the developing world. Ann Oncol. 2006; 17 Suppl 8: viii 15-viiii23.

3. Federal Ministry of Health, Sudan. 25 years strategic plan for the health Sector. 2003.

4. Chirdan LB, Bode-Thomas F, Chirdan OO. Childhood cancers: Challenges and strategies for management in developing countries. Afr J Paediatr Surg. 2009; 6 (2): 126-130.

5. Francis UA. Childhood malignancies: Implication for millennium goals. Afr $\boldsymbol{J}$ Paediatr Surg. 2009; 6 (1): 1-2.

6. Stiller CA. International patterns of cancer incidence in adolescents. Cancer Treat Rev. 2007; 33(7): 631-45.

7. Howard SC, Metzger ML, Wilimas JA, Quintana Y, Pui C, Robinson LL, et al. Childhood Cancer Epidemiology in LowIncome Countries. Cancer. 2008; 112(3): 461-72.

8. Haroun HM, Mahfouz MS, Elhaj AM. Patterns of Childhood Cancer in Children admitted to the Institute of Nuclear Medicine, Molecular Biology and Oncology (INMO), Wad Medani, Gezira State. Journal of Family \& Community Medicine. 2006; 13(2): 71-74.

9. Pearce MS, Parker L. Childhood cancer registrations in the developing world: still more boys than girls. Int J Cancer. 2001; 91(3): 402-406.

10. Samaila MO. Malignant tumours of childhood in Zaria. Afr J Paediatr Surg. 2009; 6 (1): 19-23.

11. Elmalti S, Gheriani NA, Elsahli NA, Toweir AA. Epidemiological Pattern of Childhood Malignancies in the Eastern Region of Libya. Sebha University Journal of Medical Sciences. 2002; 3(1):1-6.

12. Fischer PR, Ahuka LO, Wood PB, Lucas S. Malignant tumours in children of northeastern Zaire. A comparison of distribution patterns. Clin Pediatr (Phila). 1990; 29(2): 95-98.

13. Gyasi RK, Tettey Y. Childhood deaths from malignant neoplasms in Accra. Gana Medical Journal. 2007; 41(2): 78-82. 
14. Ocheni S, Bioha FI, Ibegbulam OG, Emodi IJ, Ikefuna AN. Changing pattern of childhood malignancies in Eastern Nigeria. West Afr Med J. 2008; 27(1): 3-6.

15. Tanko NM, Echeijoh GO, Manasseh NA, Mandong MB, Uba AF. Paediatric solid tumours in Nigerian children: A changing pattern? Afr J Paediatr Surg. 2009; 6 (1): 7-10.

16. Wessels G, Hesseling PB. Incidence and frequency rates of childhood cancer in Namibia. S Afr Med J. 1997; 87(7): 88589.
17. Hosny G, Elkaffas SM. Patterns in the incidence of paediatric cancer in Alexandria, Egypt, from 1972 t0 2001. J Egypt Public Health Assoc. 2002; 77(5-6): 451-68.

18. Uba AF, Chirdan LB. Childhood Wilms' tumour: prognostic factors in North Central Nigeria. West Afr J Med. 2007; 26(3): 22225.

19. Abuidris DO, Elimam ME, Nugud FM, Elgaili EM, Ahmed ME, Arora RS. Wilms Tumour in Sudan. Pediatr Blood Cancer. 2008; 50: 1135-1157. 